which had bcen removed two or three times from her, and her anxiety was excessive, as she tried to find out if they were all present, or if any were still missing. She kept puzzling and running her eyes over them backwards and forwards, but could not satisfy herself. She evidently had a vague notion of counting, but the figure was too large for her brain. Taking the two as they stood, dog and Damara, the comparison reflected no great honour on the man." But even if "Dinah" had been clear on this subject, it might be said that she knew each puppy personally, as collies are said to know sheep. The same remark applies generally to animals and their young. Swans, for instance, are said to know directly if one of their cygnets is missing, but it is probable that they know each young bird individually. This explanation applies with less force to the case of eggs. According to my bird-nesting recollections, which I have refreshed by more recent experience, if a nest contains four eggs, o:le may safely be taken; but if two are removed, the bird generally deserts. Here, then, it would seem as if we had some reason for supposing that there is sufficient intelligence to distinguish three from four. An interesting consideration arises with reference to the number of the victims allotted to each cell by the solitary wasps. One species of Ammophila considers one large caterpillar of Notua segetum enough; one species of Eumenes supplies its young with 5 victims; another 10,15 , and even up to 24 . The number appears to be constant in each species. How does the insect know when her task is fulfilled ? Not by the cell being filled, for if : ome be removed she does not replace them. When she has brought her complement she considers her task accomplished, whether the victims are still there or not. How, then, does she know when she has made up the number 24? Perhaps it will be said that each species feels some mysterious and innate tendency to provide a certain number of victims. This would, under no circumstances, be any explanation; but it is not in accordance with the facts. In the genus Eumenes the males are much smaller than the females. Now, in the hive-bees, humble-bees, wasps, and other insects, where such a difference occurs, but where the young are directly fed, it is of course obvious that the quantity can be proportioned to the appetite of the grub. But in insects with the habits of Eumenes and Ammophila the case is different, because the food is stored up once for all. Now, it is evident that if a female grub was supplied with only food enough for a male she would starve to death; while if a male grub were given enough for a female it would have too much. No such waste, however, occurs. In some mysterious manner the mother knows whether the egg will produce a male or female grub, and apportions the quantity of food accordingly. She does not change the species or size of her prey; but if the egg is male she supplies 5 ; if female, 10 victims. Does she count? Certainly this seems very like a commencement of arithmetic. At the same time it would be very desirable to have additional evidence how far the number is really constant. Considering how much has been written on instinct, it seems surprising that so little attention has been directed to this part of the subject. One would fancy that there ought to be no great difficulty in determining how far an animal could count; and, whether, for instance, it conld realise some very simple sum, such as that two and two make four. But when we come to consider how this is to be done the problem ceases to appear so simple. We tried our dogs by putting a a piece of bread before them and preventing them from touching it until we had counted seven. To prevent ourselves from unintentionally giving any indication we used a metronome (the instrument used for giving time when practising the pianoforte), and to make the beats more evident we attached a slender rod to the pendulum. It certainly seemed as if our dogs knew when the moment of permission had arrived ; but their movement of taking the bread was scarcely so definite as to place the matter beyond a doubt. Moreover, dogs are so very quick in seizing any indication given them, even unintentionally, that, on the whole, the attempt was not satisfactory to my mind. I was the more discouraged from continuing the experiment in this manner by an account Mr. Huggins gave me of a very intelligent dog belonging to him. A number of cards were placed on the ground, numbered respectively $1,2,3$, and so on up to Io. A question is then asked : the square root of 9 or 16 , or such a sum as $6 \times 52-3$. Mr. Huggins pointed consecutively to the cards, and the dor barked when he came to the right one. Now Mir. Huggins dill not consciously give the dog any sign, yet so quick was the dog in scizing the slightest indication, that he was able to give the correct answer. This observation seems to me of great interest in connection with the so-called "thought-reading." No one, I suppose, will imagine that there was in this case any "thought-reading" in the sense in which this word is used by Mr. Bishop and others. Evidently "Kepler" seized upon the slight indications unintentionally given by $\mathrm{Mr}$. Huggins. The observation, however, shows the great difficulty of the subject. I have ventured to bring this question before the Section partly because I shall be so much obliged if any lady or gentleman present will favour me with any suggestions; and partly in hope of inducing others with more leisure and opportunity to carry on similar observations, which I cannot but think must lead to interesting results.

Dr. Flower remarked that the crowded state of the room was sufficient evidence of the interest taken in whatever of the numerous subjects Sir John Lubbock cared to enlighten them upon. Sir John Lubbock was unable to make his dog count seven, but a dog at a place where he (Dr. Flower) was living recently certainly knew when the seventh day of the week came. The dog, most cager on every other day of the week to go for a walk, betrayed no desire to go on Sunday when his master took up hi hat and stick to go to church. It struck him that the methor which Sir John had adopted was the only one by which the could put themselves in reiation to the minds of these animalsnamely, the method of kindness and encouragement. Too many had tried to do these things by a system of intimidation and cruelty, but he did not think they could really know what dogs could do, and bring out their faculties, without patience and perseverance, encouragement, and uniform kindness.

Miss Catherine Rae explained the way in which she got a dog, within three weeks, to ring a bell. She began by letting "Tiny" smell the bone of a mutton chop, and then tied the bone to the string of the bell. At first "Tiny" was in a great tremor, but, by taking her very kindly and stroking her, she found that she could induce her to pull at the bone and so to ring the bell. After that she tied a small piece of wood to the string, but the dog would not pull it. At last she pulled her gently back till the bell rang, and in this way, in the short course of three weeks, with not more than one or two lessons a day, the dog would go and ring the bell by being told-"' 'Tiny,' go and ring the bell." At the end of three weeks she gave an evening party, and during the evening they were all electrified by the sudden and violent ringing of the bell. "Tiny" had been neglected to be indulged with any tit-bit, and had taken this means of receiving attention.

Miss Becker said, with regard to the experiments with the crow mentioned by Sir John, to show that it could not count beyond three, that something of the same kind might happen with a person. Place three eggs upon the table, and any one could say there were three; but if there were twelve he would require to count them to be sure of the number.

Mr. C. C. Walker gave an instance of a dog being taught politics. He belonged to a family where Liberal politics prevailed, and the dog showed his sympathy by growling fearfully when the name of "Dizzy" was mentioned, and at the name of his master giving expression to unbounded delight. Similar demonstrations at public meetings, he acdded, were often made with as little intelligence as those of the $\mathrm{dog}$.

Some other remarks were made, one gentleman suggesting that as long as the dog was ignorant of the words " one," "two," "three," "four," he would not be able to count or get beyond the mere perception of magnitude.

Sir John Lubbock thought with reference to the question of Sunday that there were so many slight indications in the household generally to distinguish the day that he had never been able to regard that as proof of a dog counting, although it was a very interesting fact in itself. As regards several of the other cases they were clever tricks, but his suggestion was to operate in exactly the opposite direction; not to teach the dog, but to enable the dog to communicate with us.

\section{NITROGEN IN THE SOIL}

$\mathrm{FACH}$ of the elements required for building up the frame of animals and plants is of equal importance from a scientific standpoint, but in agriculture the various salts and substances which yield food for crops or for cattle must necessarily be valued according to their cost. There are exceptions to this rule, no doubt. Gypsum is a cheap manure, but it has sometimes doubled the clover crop, and kainit salts are comparatively cheap. Yet 
for some crops, especially potatoes, in cases of a cieficient supply of potash in the soil, they have sometimes proved invaluable. In general, however, cost and efficiency are closely associated, and as plants and animals are almost alike in their chemical composition the same rule as to the value of their con-tituents holds good. You may purchase starch and the carbo-hydrates at a much lower rate than the nitrorgenous substances in food. Turnips, bread fruit, and bananas, consisting chiefly of carbohydrates, are sold by their respective growers at a very different and much lower price than milk or peas, which are rich in albuminous elements. In every form nitrogen is always comparatively costly. The albumen in eggs, the fibrine in cereals, the casein in milk, and the legumin in peas and beans, all owe their importance and cost to this particular element, which is the source of force and vigour, of the labour of the hardest-worked cattle and men, of lean meat and muscle.

Considering the limited supply of nitrogen and the cost of obtaining it, it is not suprising that it should often be present in cultivated soils in quantities insufficient for a full crop, and that the land, when dressed with salts of nitrogen, should answer to their touch as a horse does to the spur. In the Rothamsted experiments the unmanured field yielded for years about fourteen bushels, or half a crop, till a dressing of nitrogen was given to it, when immediately the crop was doubled, nitrogen having been, as it often is in clay soils, the one thing needful to a full crop. Sir John Lawes has been sometimes asked by American farmers how to restore the exhausted fertility of their fields, so that the land, yielding fourteen bushels per acre, which is about the average of corn-exporting countries, might be induced to return twice as much. It is fortunate for English farmers that Sir John can only send advice into the far West; he cannot send nitrogen.

Some years ago the agricultural community was flattered by the immediate prospect of a never failing supply of nitrogen. The marvels of chemistry and analysis had recently been un folded by the writings of Sir H. Davy and Baron Liebig, and the efficacy of guano had accustomed farmers to the new method of supplying nitrogen to the land in concentrated forms and from sources outside the farmyard. Then came the promise of obtaining nitrogen from the atmosphere. The agricultural classes are rarely much moved by anything but bad weather and falling prices, and the chemists had explained to them that the nitrogen of the atmosphere, existing as it does in a free state mixed with oxygen, was not available for agricultural purposes. If it could be induced, they were told, to enter into combination with hydrogen the result would be ammonia, an invaluable manure. This was understood by farmers, and a great sensation was occasioned among them when Mr. Nasmyth, the inventor of the steam hammer, proposed to control the supply of the most costly of plant constituents by knocking it out of the atmosphere. It is easy to see that if Mr. Nasmyth had succeeded in knocking nitrogen and hydrogen into combination at a moderate cost, a revolution in the price of manures and of food must have speedily occurred.

But as the plan failed and as plants still "live and move and have their being" in the midst of an element which they cannot feed on, it was certainly surprising to learn lately that nitrogenous manures had ceased to produce their accustomed effect. The phenomenon occurred at the Dute of Bedford's experimental farm at Woburn, where, according to official statements, the yield of wheat manured by the dung of animals fed on maize proved as abundant as the crop which followed from manure produced by the feeding of cotton cake, which enriches the excreta with far more nitrogen than that produced by feeding maize.

The Woburn experiments were instituted by the Royal Agricultural Society and were placed under the management of its chemist, the late Dr. Voelcker, for the purpose of testing the value of manure obtained by the consumption of different kinds of food and to compare the effects of such manures with those of artificial manures. It is evident that in such a comparison the land to which the various fertilisers were applied should have been of similar quality. But there are other disturbing causes which may vitiate experiments of this kind, and these were not at first generally recognised. The mistake occurred in some rotation experiments in which the manure derived from cotton cake containing about 40 per cent. of nitrogenous constituents was compared in its results with that obtained from maize, a cereal containing only to per cent. of albuminoids. The results of these experiments were known to the agricultural community before the report of Dr. John Voelcker, who has succeeded his late father as chemist to the Royal Agricultural Society, had been made, and much surprise was expressed that at the close of the second rotation the cotton cake had not shown any decided superiority over the maize. It has been recently explained in an official report on the "Objects, Plan, and Results of the Woburn Experiments," that this was "probably due to the large amount of unexhausted manure in the land." Before commencing experiments, therefore, on the comparative value of manures the land should be exhausted by repeated scourging crops, as at Rothamsted, where in some cases the deep-rooting Bokara clover has been grown for the special purpose of reducing the fertility of the soil to nil.

It has long since been established that nitrogen is neither absorbed by plants from the atmosphere nor conveyed into the soil to any appreciable extent in any way except by the direct application of manure: still there are some crops which collect nitrogen and leave the surface-soil richer than before. Red clover is usually grown as a preparation for wheat, and although clover hay must necessarily withdraw a great deal of plant-food from the soil, it does not prove exhaustive in practice because the deep and fleshy roots of the plant collect nitrogen from the subsoil and, in their decay, supply it to the growing wheat-crop. Under such circumstances a strong nitrogenous manure may not be required, and may perhaps prove less desirable than a weak manure containing less nitrogen. Enough has been said to show that the field experiments which are now becoming popular, and which are being instituted at many "stations" throughout the country, will require great care and the supervision of managers who possess a competent knowledge both of "practice and science."

H. E.

\section{UNIVERSITY AND EDUCATIONAL INTELLIGENCE}

LONDON. - In accordance with resolutions passed at the extraordinary meeting of the Convocation of the University of London held on July 28 last, an adjourned extraordinary meeting of the House was held on Tuesday week in the University Building, Burlington Gardens, which was very numerously attencled. The Chairman of Convocation (Mr. F. J. Wood, LL.D.) presided, and in his opening address explained his ruling that under the said resolutions the business pending before the former meeting might now be proceeded with, and invited the House to resume the debate accordingly. At the time of the adjournment the House had a motion before it, made by Lord Justice Fry, for the reception and adoption of the report of the special committee appointed to consider the project of the "Association for Promoting a Teaching University for London." To this motion an amendment had been moved by Mr. J. W. Bone, seconded by Mr. Philip Magnus, omitting all the words in the original motion after the word "received." At Tuesday's meeting leave was given to Lord Justice Fry to accept the amendment, which thus became a substantive motion, to which his Lordship, however, immediately proposed to add "And that the House now consider what amendments, if any, ought to be made in the said scheme, and that such amendments, if any, be by way of instruction to a committee of revision." For Lord Justice Fry's motion 76 only voted against $\mathbf{1} 22$ who negatived it. Ultimately after a three hours' sitting the debate was adjourned to 'Tuesday, December 8.

Alderman Sir R. N. Fowler, Bart., M.P., has consented to present the City and Guilds of London Institute's Scholarships, Prizes, and Certificates at a meeting to be held on Wednesday evening, December 9, at the Salters' Hall, St. Swithin's Lane, E.C. The Right Hon. the Lord Mayor will preside.

\section{SCIENTIFIC SERIALS}

Mittheilungen der Naturforschenden Gesellschaft in Bern, Nos. I064 to I09I, I883-4 (three parts).-Contributions to the doctrine of metal-poisoning, by J. Marti.-Terrestrial and fresh-water mollusca collected in the neighbourhood of Berne and Onterlacken, by G. Regelsperger.-An automatically. acting thermograph, by G. Hasler.-Influence of sexual excitation on the composition of cow's milk, by F. Schaffer.-Furthes paper on the animal world in the pile-dwellings of the Lake of Bienne, by Th. Studer. - On a parasite in the intestine of the horse, by M. Flesch.-On the nature of odorous matters and 